Article

\title{
Engineering Properties of Colorful Mortar with Inorganic Color Paste
}

\author{
Jhih-Ming Huang ${ }^{1}$, Wein-Duo Yang ${ }^{1}$, Her-Yung Wang ${ }^{2, *}$ and Tien-Chun Kao ${ }^{2}$ \\ 1 Department of Chemical and Materials Engineering, National Kaohsiung University of Science and Technology, \\ Kaohsiung City 80778, Taiwan; color.jackhuang@gmail.com (J.-M.H.); ywd@nkust.edu.tw (W.-D.Y.) \\ 2 Department of Civil Engineering, National Kaohsiung University of Science and Technology, \\ Kaohsiung City 80778, Taiwan; asd75986417@gmail.com \\ * Correspondence: wangho@nkust.edu.tw
}

Citation: Huang, J.-M.; Yang, W.-D.; Wang, H.-Y.; Kao, T.-C. Engineering Properties of Colorful Mortar with Inorganic Color Paste. Appl. Sci. 2021, 11, 6297. https://doi.org/10.3390/ app11146297

Academic Editor: José A. Orosa

Received: 2 June 2021

Accepted: 1 July 2021

Published: 7 July 2021

Publisher's Note: MDPI stays neutral with regard to jurisdictional claims in published maps and institutional affiliations.

Copyright: (C) 2021 by the authors. Licensee MDPI, Basel, Switzerland. This article is an open access article distributed under the terms and conditions of the Creative Commons Attribution (CC BY) license (https:// creativecommons.org/licenses/by/ $4.0 /)$.

\begin{abstract}
Color cement directly exposes the surface of a concrete building through concrete materials or adding color additives and other technologies to achieve a special aesthetic effect of the overall building's appearance. The multifunctionality of materials is paid increasing attention with time. This study uses additional $5 \%, 10 \%$ and $15 \%$ inorganic color paste and $20 \%$ polyacrylic emulsion to colorize mortar, and discusses the fresh properties (slump, slump flow), hardened properties (compressive strength, flexural strength, tensile strength and ultrasonic pulse velocity and durability (surface resistivity, thermal conductivity and length change) of mortar. The results show that the slump and slump flow increase with the content of inorganic color paste; the slump flow is larger than the control group and larger than $25 \mathrm{~cm}$, meaning the inorganic color paste can effectively enhance the workability of mortar. The compressive strength, flexural strength and tensile strength decrease as the inorganic color paste increases. The addition of $5 \%$ inorganic color paste still maintains certain engineering properties. The addition of polyacrylic emulsion can improve the tensile strength of mortar, which is higher than the control group. The ultrasonic pulse velocity is a little different from compressive strength, but they have similar trends, and it is higher than $3500 \mathrm{~m} / \mathrm{s}$. The durability decreases as the inorganic color paste and polyacrylic emulsion increase, meaning the content of inorganic color paste has relatively significant influence. The surface resistivity at the age of 7 days was higher than $20 \mathrm{k} \Omega-\mathrm{cm}$. The findings show that different contents of inorganic color paste and $20 \%$ polyacrylic emulsion have different degrees of influence on the engineering properties of colorful mortar.
\end{abstract}

Keywords: inorganic color paste; color; mortar; engineering properties

\section{Introduction}

Over time, many urban houses do not conform to current seismic resistance, pipeline or fire codes. In order to meet safety standards and prolong buildings' service life, the old buildings shall be renovated [1]. Therefore, the city plans are updated in many places, the urban function can be increased, the inhabited environment can be improved, the public interest can be increased, the city is beautified and the building's service life is prolonged [2]. The construction industry is deeply correlated with Taiwan's economic development. Manpower shortage has been a problem in Taiwan through the ages, and as the construction industry is a highly labor-intensive industry, the labor shortage heavily damages the industry [3]. Improving the external wall construction material can enhance building esthetics and reduce the construction steps, so as to reduce the manpower demand.

Color cement directly exposes the architectural or structural surface of concrete buildings through special concrete materials (or adding color additives), formwork, pouring, and maintenance technology to achieve a special aesthetic effect of the overall architectural appearance. Because of the strong color cement decorative mortar, substrate adhesion is very suitable for the surface decoration of various substrates. In addition, the colored 
cement decorative mortar has a rich color and changeable texture. It can be widely used in the exterior walls of houses, villas, office buildings, hospitals, factories and other buildings. It also has the various properties of structural concrete and good color durability [4]; however, there are unsatisfactory places in the application of colored cement decorative mortar; the most common one is easy frosting [5,6]. In addition, due to the batch stability of raw materials, the amount of water added during construction, and the construction environment, may cause the appearance of color difference. The color difference of colored cement decorative mortar is also an important research topic [7].

Colorful mortar is mixed with inorganic pigments and polyacrylic emulsion. The pigments include inorganic pigment, organic pigment and synthetic pigment [8]. Organic pigment is likely to fade under the effect of UV, high temperature or rainwater, and it shall not be mixed with mortar. Iron oxide pigment has good color ability, it is very common on the market, and its properties meet the requirements of this study, so this study uses iron oxide pigment to strengthen the color of mortar. Iron oxide pigment has been extensively used for producing coatings, plastics, rubber, ceramics, paper, ink, art pigments, industrial chemicals, animal feed, cosmetics and magnetic recording materials. Oxide pigment is used for producing anti-corrosive primer in paint industry, used as the colorant for such rubber goods as tires and triangular belts in rubber industry, and mixed with cement to manufacture artificial marble, terrazzo floor, imitation glazed tiles and mosaic tiles. Additionally, iron oxide pigment is usually used as the colorant and filling agent for asbestos, man-made leather and leather [1]. The mortar mixed with polyacrylic emulsion, which is a white emulsion-like aqueous material, forms a colloid-like interface after reaction, enhancing the mechanical properties of mortar, including impermeability and wear resistance [9]. This effect can reduce the construction procedure of external rendering layer, so as to reduce the manpower demand. This study uses $5 \%, 10 \%$ and $15 \%$ inorganic color pastes and $20 \%$ polyacrylic emulsion to colorize mortar, hoping to obtain an appropriate mix proportion, and to achieve workability, durability, safety, ecology, economy and esthetic appearance of works.

\section{Research Materials and Methods}

\subsection{Research Materials}

The materials used in the color mortar in this study are cement, inorganic color paste, polyacrylic emulsion and fine aggregate. The test materials are as follows:

(1) Cement: In this study, general cement made by the Taiwan Cement Corp. (Taipei, Taiwan) is tested, which is Type I ordinary Portland cement according to ASTM C150 [10]. The specific gravity is about 3.15, as shown in Figure 1.

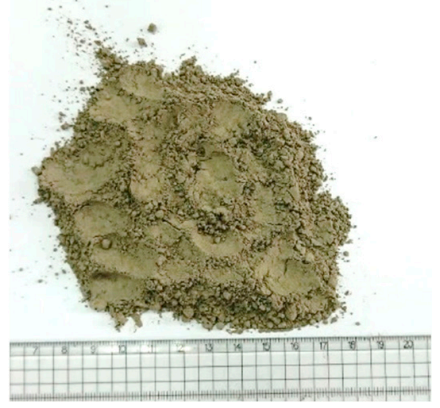

(a)

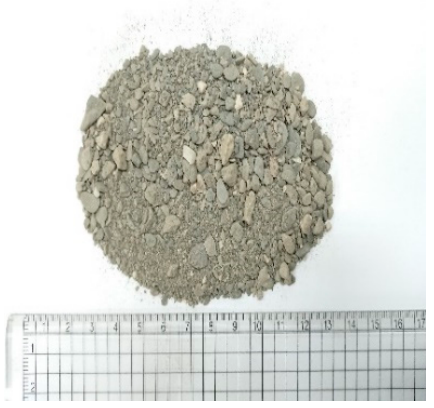

(b)

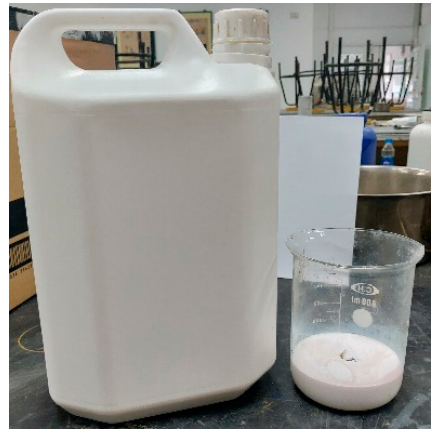

(c)

Figure 1. Experiment material. (a) Cement; (b) fine aggregate; (c) polyacrylic emulsion.

(2) Mixing water: meeting the ASTM C1602 [11] mixing water standard specification.

(3) Polyacrylic emulsion: provided by Fushibao Material Technology Co., Ltd. (Taipei, Taiwan), as shown in Figure 1. The basic properties are shown in Table 1. 
Table 1. The physical and chemical properties of polyacrylic emulsion.

\begin{tabular}{cccc}
\hline \multicolumn{2}{c}{ Physical Properties } & \multicolumn{2}{c}{ Chemical Contents (\%) } \\
\hline Solid content & $50 \pm 1 \%$ & PolyAcrylic Emulsion & $50 \pm 1$ \\
Viscosity & Under $500 \mathrm{cPs}$ & Water & $50 \pm 1$ \\
pH & $9.0-10.0$ & - & - \\
\hline
\end{tabular}

(4) Fine aggregate: natural river sand from Ligang River; the specific gravity is 2.65 and the water absorption is 2.0\%, according to ASTM C33 [12]. Shown in Figure 1.

(5) Inorganic color paste: provided by Fushibao Material Technology Co., Ltd., as shown in Figure 2; the basic properties are shown in Table 2.

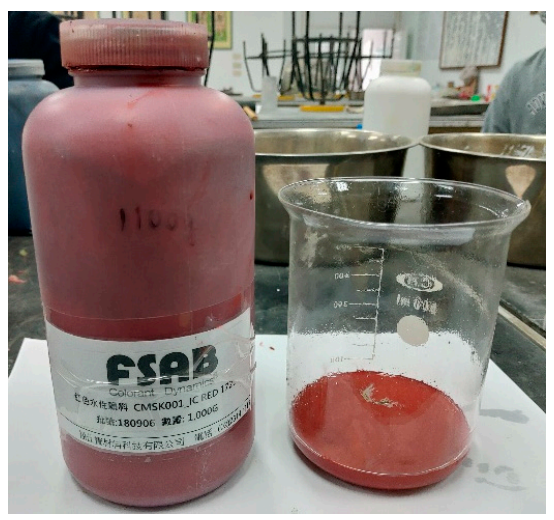

(a)

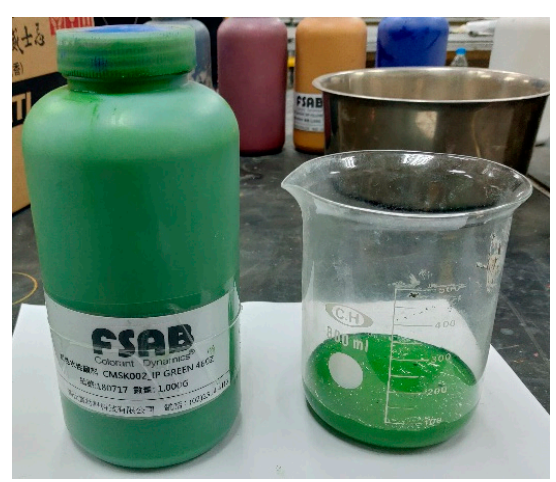

(c)

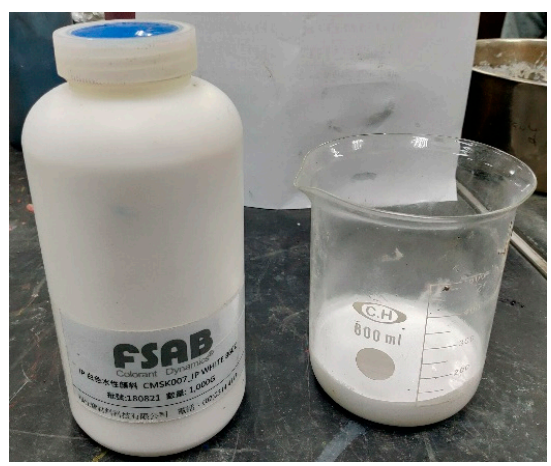

(e)

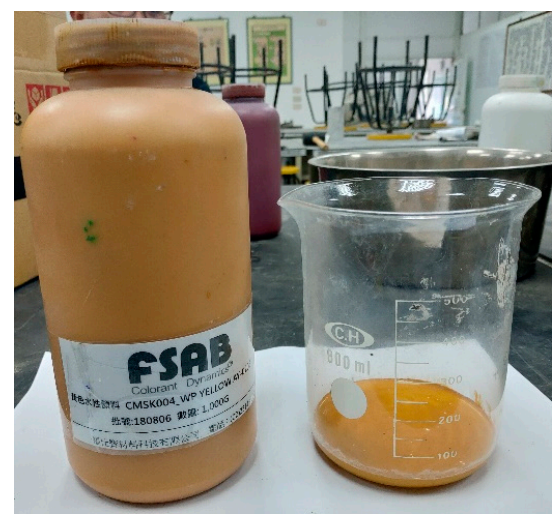

(b)

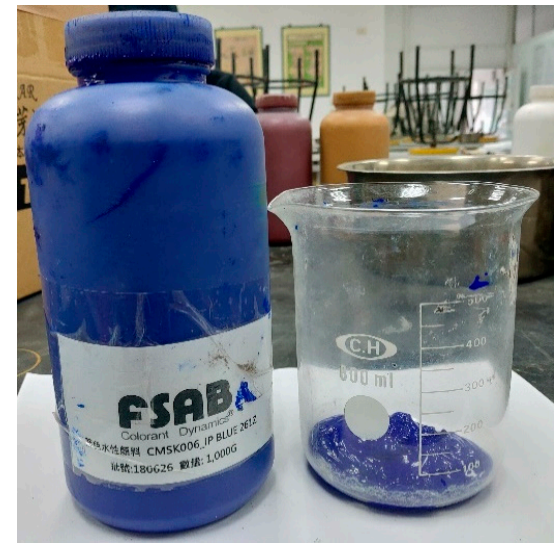

(d)

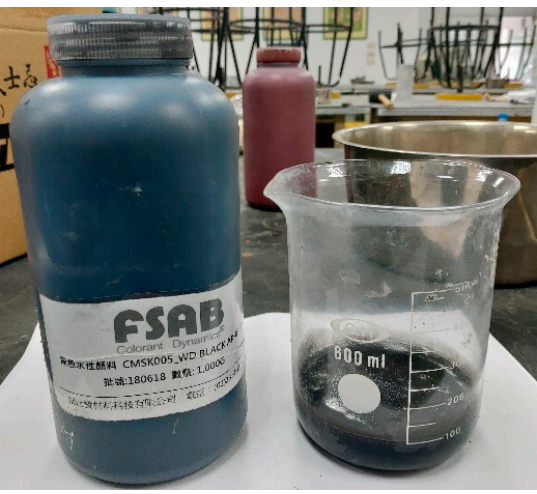

(f)

Figure 2. Experiment material—inorganic color paste. (a) red inorganic color paste; (b) yellow inorganic color paste; (c) green inorganic color paste; (d) blue inorganic color paste; (e) white inorganic color paste; (f) black inorganic color paste. 
Table 2. The physical properties of inorganic color paste.

\begin{tabular}{|c|c|c|c|c|c|c|}
\hline Physical Properties color & Red & Yellow & Green & Blue & White & Black \\
\hline Grind-meter value $(\max , \mu \mathrm{m})$ & 15 & 15 & 20 & 20 & 10 & 10 \\
\hline Viscosity $(\mathrm{KU})$ & 86 & 79 & 84 & 75 & 83 & 86 \\
\hline Non-volatile (\%) & 75.4 & 54.5 & 58.5 & 58.9 & 72.3 & 64.6 \\
\hline Specific Gravity & 2.08 & 1.67 & 1.74 & 1.45 & 2.07 & 1.93 \\
\hline $\mathrm{pH}$ & 7.92 & 7.9 & 8.2 & 7.02 & 7.32 & 7.7 \\
\hline Tinting shade $(\Delta \mathrm{E})$ & -0.14 & 0.25 & 0.34 & 0.31 & 0.03 & 0.43 \\
\hline Tinting Strength (\%) & 99.4 & 99.35 & 98.7 & 102.16 & 99.86 & 99.39 \\
\hline
\end{tabular}

\subsection{Test Items and Methods}

The main test items in this study include slump, slump flow, compressive strength, flexural strength, tensile strength, ultrasonic pulse velocity, surface resistivity, thermal conductivity and length change. The test specifications are described below.

(1) Slump: tested referring to ASTM C143 [13]. A minislump cone is used to perform three tests, and the average is taken to judge the slump of the mortar.

(2) Slump flow: tested according to ASTM C230 [14], aiming to determine the standard flow value of mortar. The test must be measured four times after 25 drops, and the average of the four measurements is the slump flow value of the sample.

(3) Compressive strength: 342 pieces of $5 \mathrm{~cm} \times 5 \mathrm{~cm} \times 5 \mathrm{~cm}$ test cube poured according to ASTM C109 [15].

(4) Flexural strength: 342 pieces of $4 \mathrm{~cm} \times 4 \mathrm{~cm} \times 16 \mathrm{~cm}$ cuboid specimen poured according to ASTM C348 [16], so as to analyze the flexural resistance of different mortars.

(5) Tensile strength: 342 pieces of splayed specimen poured according to ASTM C190 [17].

(6) Ultrasonic pulse velocity: measured by using two probes to contact the specimen surface according to ASTM C597 [18]. The transmitter sound pulse is transferred into the specimen, and the pulse transmission time is measured to calculate the pulse velocity of ultrasound in the specimen.

(7) Surface resistivity: measured according to ASTM C876 [19]. It can be regarded as an indirect index of the internal porosity and connectivity of mortar. The higher the resistivity is, the less surface current flows through the specimen, representing higher compactness and better durability of the specimen.

(8) Thermal conductivity: calculated from the correlation between specimen temperature difference and time variation according to ASTM E1225 [20]. Higher conductivity coefficient represents lower porosity of the specimen and better compactness, but a weaker thermal insulation effect.

(9) Length changes at different ages: measured according to ASTM C157 [21] to judge the volume stability of mortar.

\subsection{Test Variables and Mix Proportions}

In this test, three specimens are used for each age and ratio, and 342 specimens are used for the Compressive, Flexural and Tensile strength. The test variables are listed below, and the mix proportions are shown in Table 3.

Table 3. W/C 0.4 Mixture proportions of mortar.

\begin{tabular}{|c|c|c|c|c|c|c|}
\hline $\operatorname{AM}(\%)$ & $\begin{array}{l}\text { PolyAcrylic Emulsion } \\
\left(\mathrm{kg} / \mathrm{m}^{3}\right)\end{array}$ & $\operatorname{AM}(\%)$ & $\begin{array}{l}\text { Color Paste } \\
\left(\mathrm{kg} / \mathrm{m}^{3}\right)\end{array}$ & $\begin{array}{l}\text { Cement } \\
\left(\mathrm{kg} / \mathrm{m}^{3}\right)\end{array}$ & $\underset{\left(\mathrm{kg} / \mathrm{m}^{3}\right)}{\text { Sand }}$ & $\begin{array}{l}\text { Water } \\
\left(\mathrm{kg} / \mathrm{m}^{3}\right)\end{array}$ \\
\hline 0 * & $0 *$ & 0 * & $0 *$ & & & \\
\hline 20 & 124.85 & $\begin{array}{c}5 \\
10 \\
15\end{array}$ & $\begin{array}{c}93.64 \\
124.85 \\
156.07\end{array}$ & 624.26 & 1534.88 & 187.28 \\
\hline
\end{tabular}

Remarks: * represents the control group; Mixing water does not contain the moisture of the color paste. 
(1) Water-cement ratio: 0.4

(2) Polyacrylic emulsion content: $20 \%$

(3) Inorganic color paste content: 5, 10 and $15 \%$

(4) Age: 3, 7, 28, 56, 91 and 120 days

(5) Color variables: control group, red, yellow, green, blue, white, and black

\section{Results and Discussion}

\section{(1) Slump}

As shown in Figure 3, the slump value of the control group mortar without inorganic color paste is $0.1 \mathrm{~cm}$, and the slump values of the colorful mortar with different color contents are higher than $8 \mathrm{~cm}$; thus, the effect of inorganic color paste on the slump is relatively obvious. The composition of dispersant in the inorganic color paste is similar to the composition of a water-reducing agent and the water content and dispersant content in different color pastes are unclear, so the colorful mortar with inorganic color paste has higher slump. When the content of inorganic color paste increases from $5 \%$ to $10 \%$, the slump growth rates of yellow, green, white, red, blue and black are 2.9, 5.0, 10.0, 10.5, 14.3 , and $18.2 \%$. When the substitution amount increases from $10 \%$ to $15 \%$, the slump growth rates increase from $5 \%$ to $10 \%$, meaning $5 \%$ to $10 \%$ have a relatively obvious growth rate; this may because the influence of dispersant content in the inorganic color paste on the mortar has been maximized, and thus the increase in content has no obvious help. Therefore, the growth amplitude is small when the content is $15 \%$, and the black inorganic color paste has the most obvious effect on slump value among various colors, the yellow inorganic color paste has insignificant influence on slump, and overall the inorganic color paste can increase mortar slump, contributing to the workability of mortar.

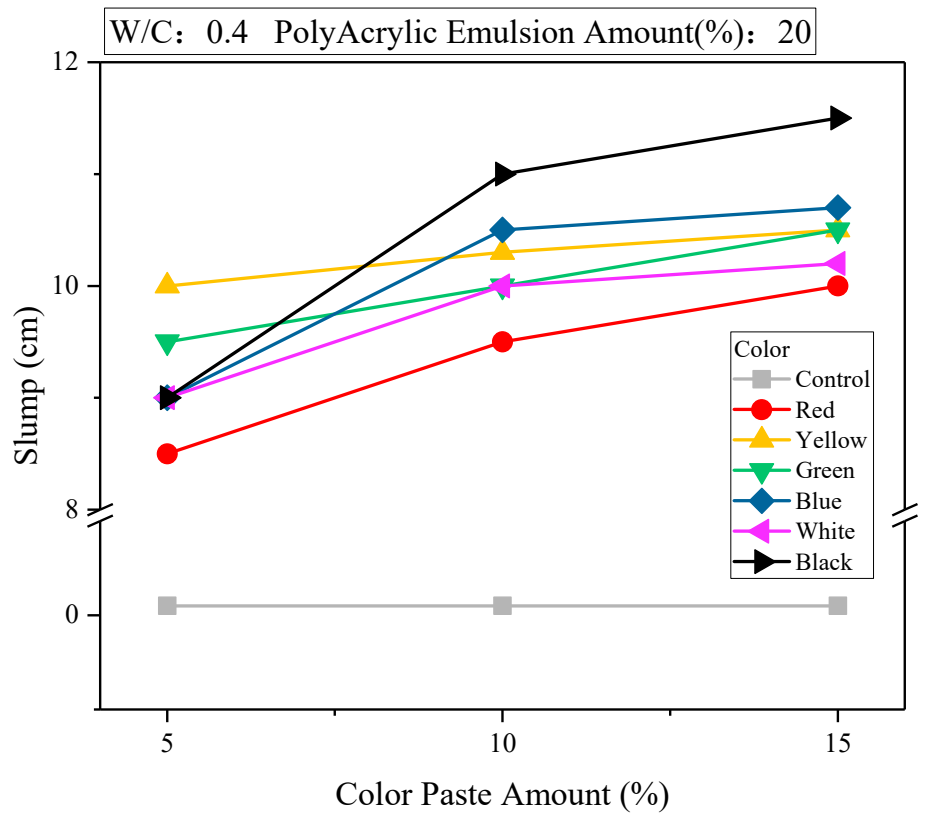

Figure 3. Slump of mortar with different proportions of inorganic color paste.

(2) Slump flow

As shown in Figure 4, the slump flow of the control group is $11.5 \mathrm{~cm}$, and the slump flows of colorful mortars with $5 \%, 10 \%$ and $15 \%$ red inorganic color pastes are 26.8, 26.9 and $27.2 \mathrm{~cm}$, meaning the slump flow increases with content. When the content of inorganic color paste is $10 \%$, the slump flows of the colorful mortars in different colors (red, yellow, green, blue, white, and black) are 26.9, 28.4, 25.5, 26.8, 26.6 and $28.5 \mathrm{~cm}$, respectively. The slump flows of various colors are larger than the control group and larger than $25 \mathrm{~cm}$, 
meaning the inorganic color paste can effectively enhance the workability of mortar. As the slump flows in this test are larger than the upper limit $25 \mathrm{~cm}$ of the test instrument, a concrete slump plate is fixed above the instrument to enlarge the data measuring area.

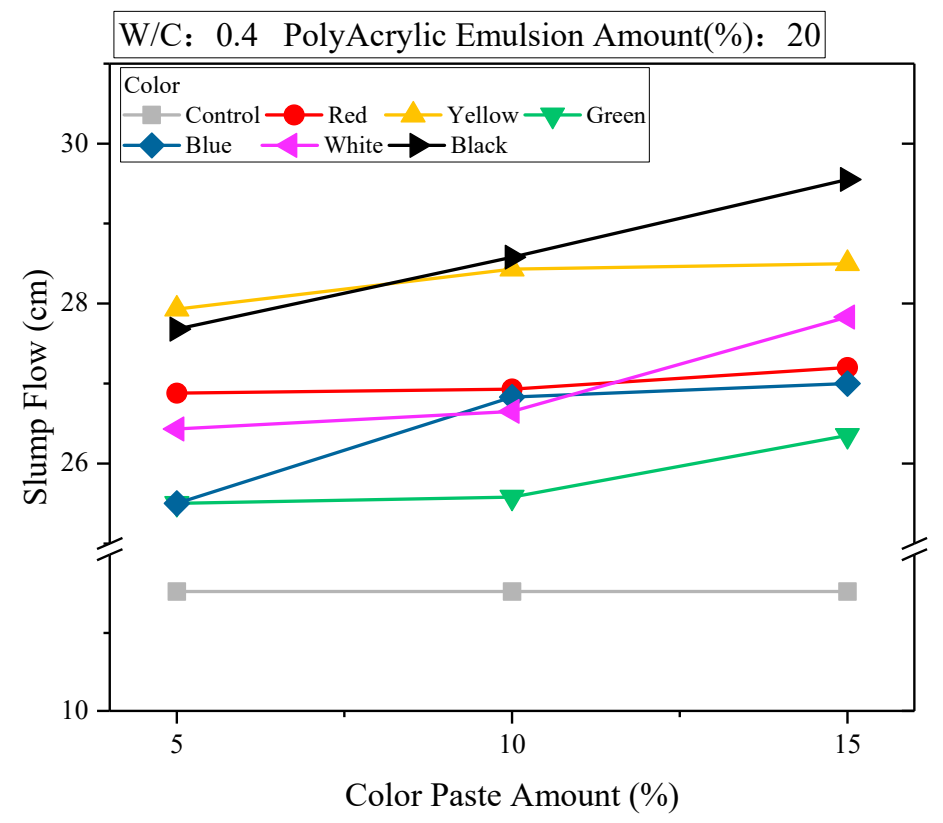

Figure 4. Slump flow of mortar with different proportions of inorganic color paste.

\section{(3) Compressive strength}

As shown in Table 4 and Figure 5, the compressive strength of mortar increases with age. The compressive strengths of the control group mortar at the ages of 3 days 28 days and 120 days are $33.81,38.57$ and $41.2 \mathrm{MPa}$. The growth of compressive strength during the age of 3 to 28 days is about $12.34 \%$, and the growth during the age of 28 to 120 days is about $6.82 \%$. The compressive strengths of colorful mortar with $10 \%$ red inorganic color paste on Day 3, Day 28 and Day 120 are 15.97, 26.75 and $38.36 \mathrm{MPa}$. The compressive strengths of colorful mortar with 10\% yellow inorganic color paste on Day 3, Day 28 and Day 120 are 15.81, 33.54 and $40.92 \mathrm{MPa}$. The compressive strengths of colorful mortar with 15\% black inorganic color paste on Day 3, Day 28 and Day 120 are 14.68, 30.68 and 39.09 MPa. The growth of compressive strength during the age of 3 days to 28 days is $40.3-52.86 \%$ and the growth during the age of 28 days to 120 days is $22-43.4 \%$; there is significant growth compared to the control group. This may because the addition of inorganic color paste results in excessive mixing water, the porosity in the specimen is increased, the compressive strength decreases at a short age, and the compressive strength increases with age due to cement hydration and polyacrylic emulsion hardening [22].

At the age of 28 days, the compressive strengths of color cement with $5 \%, 10 \%$ and $15 \%$ red inorganic color pastes are 31.14, 26.75 and $23.21 \mathrm{MPa}$, the compressive strengths of color cement with yellow inorganic color paste are $34.31,33.54$ and $33.15 \mathrm{MPa}$, the compressive strengths of black inorganic color paste are 31.74, 30.68 and $29.08 \mathrm{MPa}$. The results show that the compressive strengths of the three inorganic color pastes decrease as the content increases. The compressive strength of mortar with $5 \%$ inorganic color paste is close to the control group, and the yellow inorganic color paste is the closest to the control group. The $5 \%$ inorganic color paste has less effect on the compressive strength of mortar, the contents $10 \%$ and $15 \%$ have relatively significant effect. It is because higher content of inorganic color paste influences the water-cement ratio more significantly. 
Table 4. Compressive strength of mortar with different proportions of polyacrylic emulsion and inorganic color paste.

\begin{tabular}{|c|c|c|c|c|c|c|c|c|}
\hline \multirow[b]{2}{*}{ Color } & \multicolumn{2}{|c|}{ AM (\%) } & \multirow[b]{2}{*}{3} & \multicolumn{2}{|c|}{ Age (Days) } & \multicolumn{2}{|c|}{ Unit: MPa } & \multirow[b]{2}{*}{120} \\
\hline & $\begin{array}{l}\text { PolyAcrylic } \\
\text { Emulsion }\end{array}$ & $\begin{array}{l}\text { Color } \\
\text { Paste }\end{array}$ & & 7 & 28 & 56 & 91 & \\
\hline Control & 0 & 0 & 33.81 & 34.48 & 38.57 & 39.04 & 39.57 & 41.2 \\
\hline \multirow{3}{*}{ Red } & \multirow{3}{*}{20} & 5 & 16.74 & 22.06 & 31.14 & 37.91 & 39.03 & 41.32 \\
\hline & & 10 & 15.97 & 21.5 & 26.75 & 36.57 & 37.53 & 38.36 \\
\hline & & 15 & 14.66 & 17.92 & 23.21 & 33.62 & 36.45 & 37.52 \\
\hline \multirow{3}{*}{ Yellow } & \multirow{3}{*}{20} & 5 & 18.63 & 27.12 & 34.31 & 40.22 & 40.98 & 42.47 \\
\hline & & 10 & 15.81 & 26.93 & 33.54 & 38.36 & 39.67 & 40.92 \\
\hline & & 15 & 14.24 & 24.52 & 33.15 & 36.37 & 37.09 & 39.42 \\
\hline \multirow{3}{*}{ Green } & \multirow{3}{*}{20} & 5 & 16.04 & 21.05 & 26.99 & 30.63 & 32.98 & 35.52 \\
\hline & & 10 & 14.41 & 18.52 & 23.99 & 28.62 & 32.45 & 34.67 \\
\hline & & 15 & 12.45 & 15.65 & 22.09 & 23.96 & 28.78 & 30.32 \\
\hline \multirow{3}{*}{ Blue } & \multirow{3}{*}{20} & 5 & 15.74 & 22.55 & 29.26 & 33.25 & 35.76 & 41.03 \\
\hline & & 10 & 15.17 & 21.44 & 26.67 & 31.41 & 33.69 & 35.16 \\
\hline & & 15 & 14.13 & 20.39 & 25.17 & 28.89 & 31.97 & 33.2 \\
\hline \multirow{3}{*}{ White } & \multirow{3}{*}{20} & 5 & 17.2 & 21.91 & 28.99 & 34.8 & 34.87 & 37.79 \\
\hline & & 10 & 16.16 & 21.29 & 27.94 & 33.9 & 34.18 & 36.99 \\
\hline & & 15 & 14.48 & 21.24 & 26.36 & 32.82 & 33.37 & 36.61 \\
\hline \multirow{3}{*}{ Black } & \multirow{3}{*}{20} & 5 & 16.71 & 21.89 & 31.74 & 35.41 & 38.24 & 40.46 \\
\hline & & 10 & 14.68 & 21.18 & 30.68 & 32.63 & 36.57 & 39.09 \\
\hline & & 15 & 14.27 & 17.93 & 29.08 & 30.29 & 31.09 & 32.7 \\
\hline
\end{tabular}

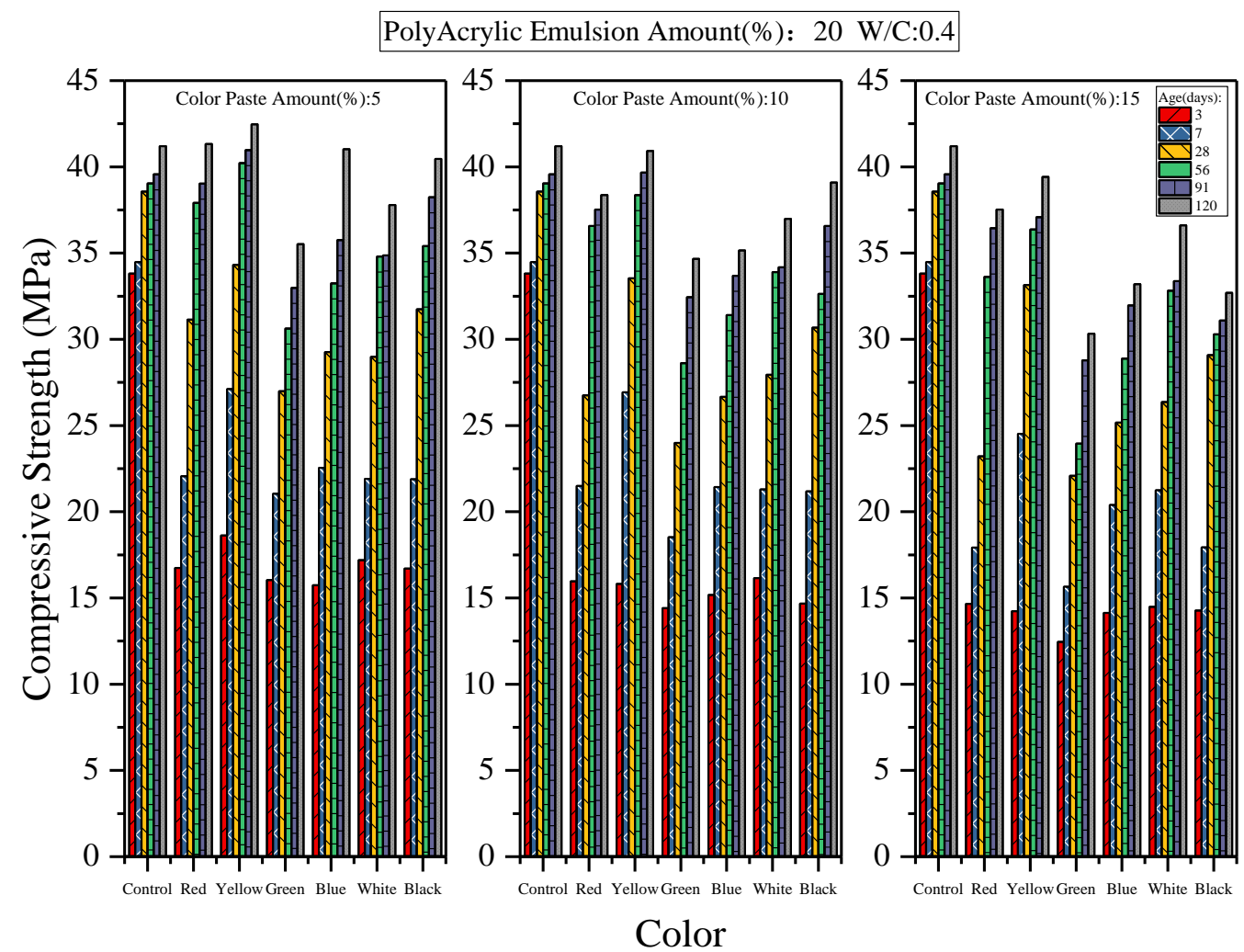

Figure 5. W/C 0.4 Compressive strength of mortar with different proportions of inorganic color paste. 


\section{(4) Flexural strength}

As shown in Figure 6, the flexural strength of colorful mortar increases with age. At the age of 28 days, when the content of inorganic color paste increases from $5 \%$ to $15 \%$, the flexural strength decreases from 10.3-13.0 MPa to 8.9-11.5 MPa, meaning the addition of inorganic color paste can influence the flexural strength of mortar. When the content of inorganic color paste is $5 \%$, the flexural strength of colorful mortar is higher than the control group by 0.6-1.1 MPa at the age of 56 days; that of blue inorganic color paste is lower than the control group by $0.2-4.2 \mathrm{MPa}$ at all ages, meaning the blue inorganic color paste has relatively significant influence on flexural strength. As the content of inorganic color paste increases to $15 \%$, the flexural strength of colorful mortar other than white inorganic color paste only approaches the control group, while the flexural strength of white inorganic color paste is higher than the control group by $0.1 \mathrm{MPa}$ at the age of 120 days, meaning the content $15 \%$ of inorganic color paste has relatively significant influence on flexural strength, and the white inorganic color paste can effectively enhance flexural strength at a late age. The addition of polyacrylic emulsion to colorful mortar can effectively enhance the flexural strength, and the property is better than compressive strength.

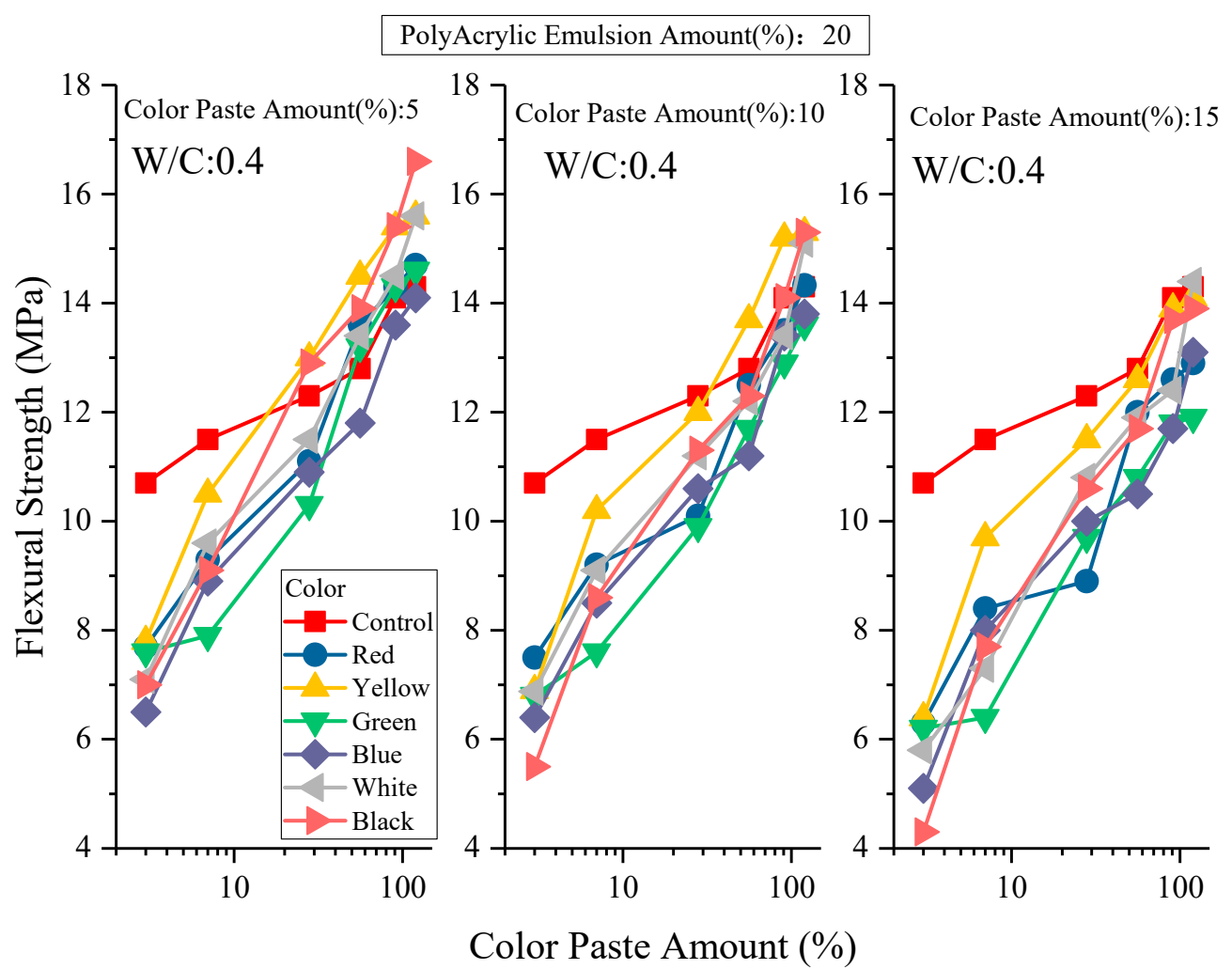

Figure 6. Flexural strength of mortar with different proportions of inorganic color paste.

(5) Tensile strength

As shown in Figure 7, the tensile strengths of colorful mortar without color paste (control group) at the ages of 3, 28 and 120 days are 4.38, 5.67 and 6.92 MPa. The tensile strengths of colorful mortar with $5 \%$ inorganic color paste at the three ages are 3.96 4.96 MPa, 6.20 7.58 MPa and 8.33 9.17 MPa. The tensile strengths of colorful mortar with 10\% inorganic color paste are 3.83 4.08 $\mathrm{MPa}, 5.80 \sim 7.04 \mathrm{MPa}$ and 7.80 8.96 MPa. The tensile strengths of colorful mortar with $15 \%$ inorganic color paste at the three ages are 3.42 3.96 MPa, 4.79 6.58 MPa and 7.13 8.21 MPa. The results show that the tensile strengths of various contents and various colors at the age of 120 days are higher than the control group, and the tensile strength of colorful mortar from the age of 28 days to the age of 120 days (excluding various contents of red inorganic color paste and $15 \%$ black 
inorganic color paste) is lower than the control group, meaning the mortar has better tensile strength at the age of 28 days. This may because the polyacrylic emulsion can improve the tensile property of mortar.

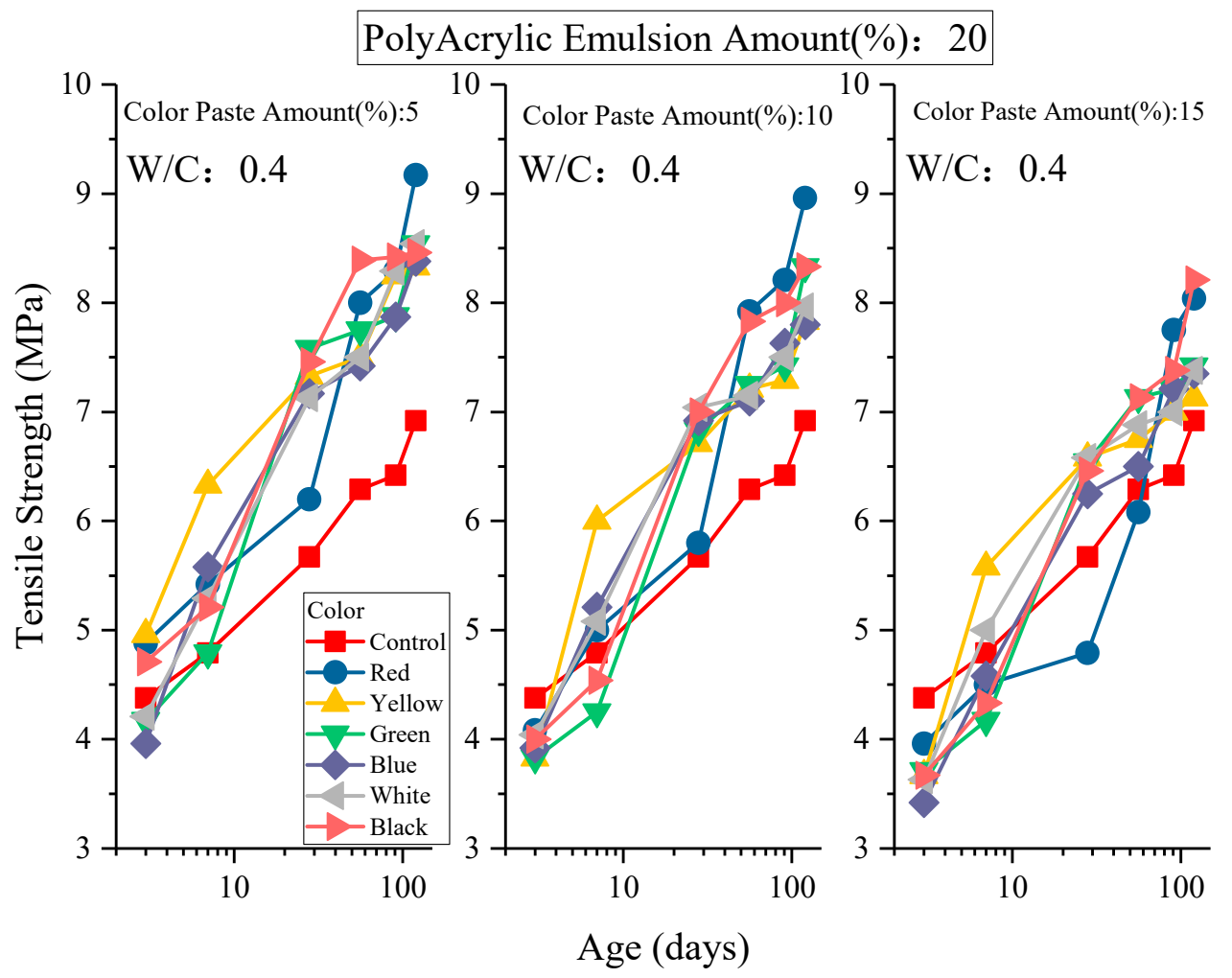

Figure 7. Tensile strength of mortar with different proportions of inorganic color paste.

(6) Ultrasonic pulse velocity

As shown in Table 5 and Figure 8, the ultrasonic pulse velocity of the control group at the age of 3 days is $4037 \mathrm{~m} / \mathrm{s}$, at the age of 28 days is $4413 \mathrm{~m} / \mathrm{s}$, and the growth of ultrasonic pulse velocity of the control group during the age of 3 to 28 days is about $8.53 \%$. The ultrasonic pulse velocity at the age of 120 days is $4479 \mathrm{~m} / \mathrm{s}$, and the growth of ultrasonic pulse velocity of the control group during the age of 28 to 120 days is about $1.49 \%$. When the content of inorganic color paste is $5 \%$, the ultrasonic pulse velocity at the age of 3 days is $3533 \sim 3799 \mathrm{~m} / \mathrm{s}$, that at the age of 28 days is $3770 \sim 4010 \mathrm{~m} / \mathrm{s}$, that at the age of 120 days is $3917 \sim 313 \mathrm{~m} / \mathrm{s}$, and the growth of ultrasonic pulse velocity during the age of 3 to 28 days is $5.52 \sim 11.67 \%$, while that during the age of 28 to 120 days is $2.22 \sim 6.74 \%$. When the content of inorganic color paste is $15 \%$, the ultrasonic pulse velocity at the age of 3 days is $3376.67 \sim 3632.67 \mathrm{~m} / \mathrm{s}$, that at the age of 28 days is $3700 \sim 3949 \mathrm{~m} / \mathrm{s}$, the growth of ultrasonic pulse velocity during the age of 3 to 28 days is $3.22 \sim 8.27 \%$, the ultrasonic pulse velocity at the age of 120 days is $3750 \sim 4167 \mathrm{~m} / \mathrm{s}$, and the growth of ultrasonic pulse velocity during the age of 28 to 120 days is $2.74 \sim 7.49 \%$. The results show that the ultrasonic pulse velocity increases with age, and the ultrasonic pulse velocities of various colors and various contents at various ages are lower than the control group. This may because there are bubbles formed when the polyacrylic emulsion is being mixed with mortar and the air cannot be discharged effectively during compacting, resulting in a lower ultrasonic pulse velocity than the control group. A certain compressive strength can be provided after the polyacrylic emulsion is hardened, and the hydration product cannot effectively fill the pores, so that the ultrasonic pulse velocity is lower than the control group. 
Table 5. UPV of mortar with different proportions of polyacrylic emulsion and inorganic color paste.

\begin{tabular}{|c|c|c|c|c|c|c|c|c|}
\hline \multirow[b]{2}{*}{ Color } & \multicolumn{2}{|c|}{ AM (\%) } & \multirow[b]{2}{*}{3} & \multicolumn{2}{|c|}{ Age (Days) } & \multicolumn{2}{|c|}{ Unit:m/s } & \multirow[b]{2}{*}{120} \\
\hline & $\begin{array}{l}\text { PolyAcrylic } \\
\text { Emulsion }\end{array}$ & $\begin{array}{l}\text { Color } \\
\text { Paste }\end{array}$ & & 7 & 28 & 56 & 91 & \\
\hline Control & 0 & 0 & 4037 & 4307 & 4414 & 4465 & 4468 & 4479 \\
\hline \multirow{3}{*}{ Red } & \multirow{3}{*}{20} & 5 & 3660 & 4004 & 4046 & 4067 & 4147 & 4286 \\
\hline & & 10 & 3635 & 3979 & 4004 & 4024 & 4088 & 4227 \\
\hline & & 15 & 3633 & 3917 & 3949 & 4004 & 4023 & 4167 \\
\hline \multirow{3}{*}{ Yellow } & \multirow{3}{*}{20} & 5 & 3799 & 4035 & 4147 & 4172 & 4266 & 4321 \\
\hline & & 10 & 3754 & 3979 & 4010 & 4100 & 4167 & 4313 \\
\hline & & 15 & 3615 & 3901 & 3941 & 3949 & 3979 & 4195 \\
\hline \multirow{3}{*}{ Green } & \multirow{3}{*}{20} & 5 & 3660 & 3827 & 3920 & 3949 & 3992 & 4144 \\
\hline & & 10 & 3571 & 3717 & 3827 & 3846 & 3930 & 4056 \\
\hline & & 15 & 3377 & 3484 & 3489 & 3495 & 3573 & 3750 \\
\hline \multirow{3}{*}{ Blue } & \multirow{3}{*}{20} & 5 & 3615 & 3812 & 3827 & 3917 & 4000 & 4085 \\
\hline & & 10 & 3574 & 3763 & 3770 & 3850 & 3949 & 4033 \\
\hline & & 15 & 3571 & 3660 & 3700 & 3800 & 3850 & 3901 \\
\hline \multirow{3}{*}{ White } & \multirow{3}{*}{20} & 5 & 3531 & 3878 & 4000 & 4035 & 4041 & 4133 \\
\hline & & 10 & 3533 & 3671 & 3919 & 3937 & 3941 & 4111 \\
\hline & & 15 & 3473 & 3533 & 3617 & 3660 & 3752 & 3799 \\
\hline \multirow{3}{*}{ Black } & \multirow{3}{*}{20} & 5 & 3660 & 3866 & 3917 & 3917 & 3930 & 4004 \\
\hline & & 10 & 3614 & 3752 & 3827 & 3878 & 3905 & 3917 \\
\hline & & 15 & 3530 & 3689 & 3803 & 3850 & 3867 & 3917 \\
\hline
\end{tabular}

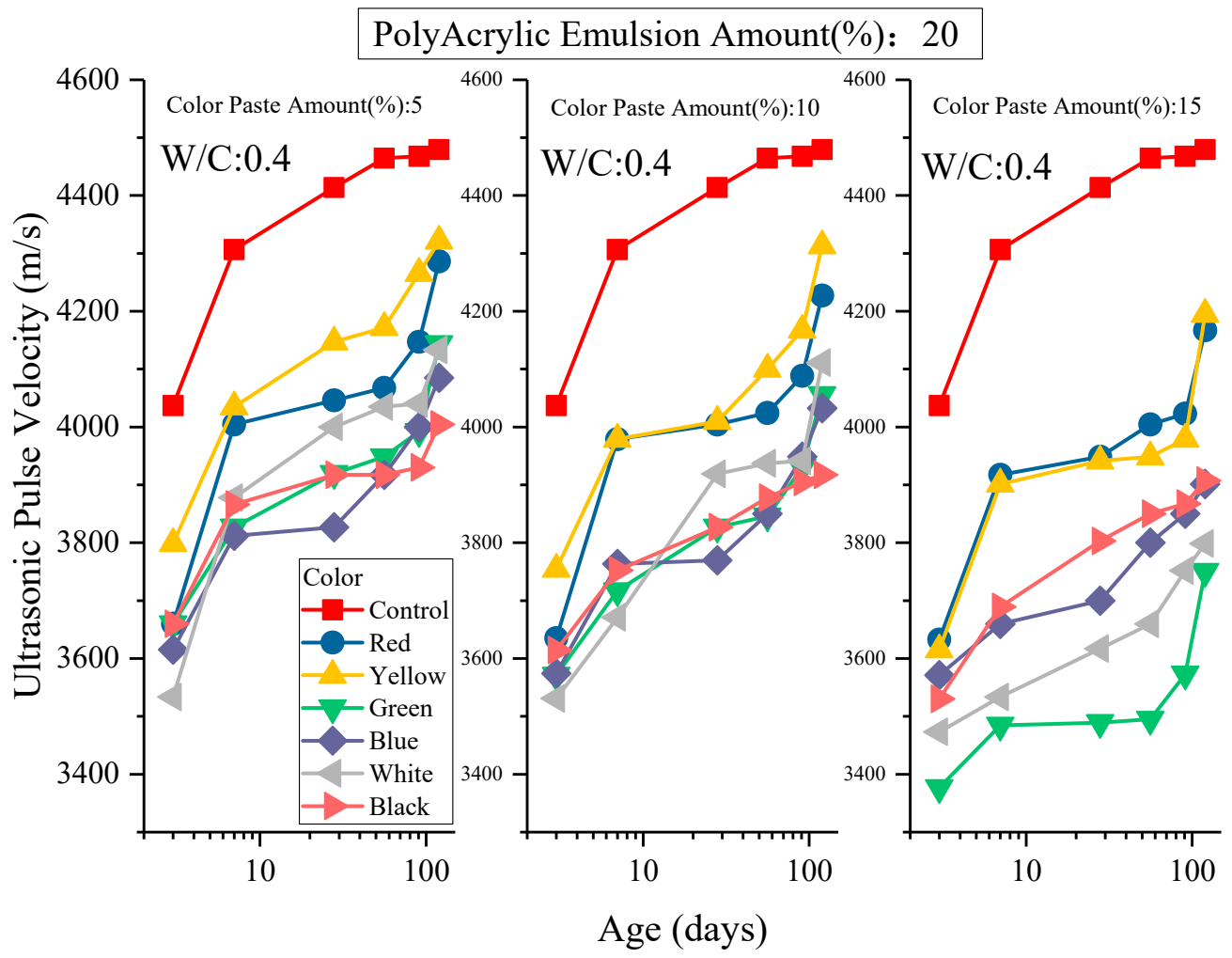

Figure 8. Ultrasonic Pluses Velocity of mortar with different proportions of Inorganic Color Paste.

(7) Surface resistivity

As shown in Figure 9, the surface resistivities of the control group at different ages ( 3 days, 28 days and 120 days) are 25,45 and $99 \mathrm{k} \Omega-\mathrm{cm}$. When the content of inorganic 
color paste is $5 \%$ at the age of 28 days, the surface resistivities of colors are $30 \sim 51 \mathrm{k} \Omega$ $\mathrm{cm}$. When the content is $10 \%$ at the age of 28 days, the surface resistivities of colors are $28 \sim 49 \mathrm{k} \Omega-\mathrm{cm}$. When the content is $15 \%$ at the age of 28 days, the surface resistivities of colors are $25 \sim 47 \mathrm{k} \Omega-\mathrm{cm}$. When the content of inorganic color paste is $5 \%$ at the age of 120 days, the surface resistivities of colors are $91 \sim 99 \mathrm{k} \Omega-\mathrm{cm}$. When the content is $10 \%$ at the age of 120 days, the surface resistivities of colors are 70 91 $\mathrm{k} \Omega-\mathrm{cm}$. When the content is $15 \%$ at the age of 120 days, the surface resistivities of colors are $60 \sim 90 \mathrm{k} \Omega-\mathrm{cm}$. The higher the surface resistivity is, the higher is the resistance to the migration of ions on the specimen surface, and the invasion of adverse ions is more difficult. Therefore, if the surface resistivity is higher than $20 \mathrm{k} \Omega-\mathrm{cm}$, it means that the specimen has good compactness [23,24]. The surface resistivity of all variables at the age of 7 days is higher than $20 \mathrm{k} \Omega-\mathrm{cm}$ in this study, meaning the specimens have good surface compactness.

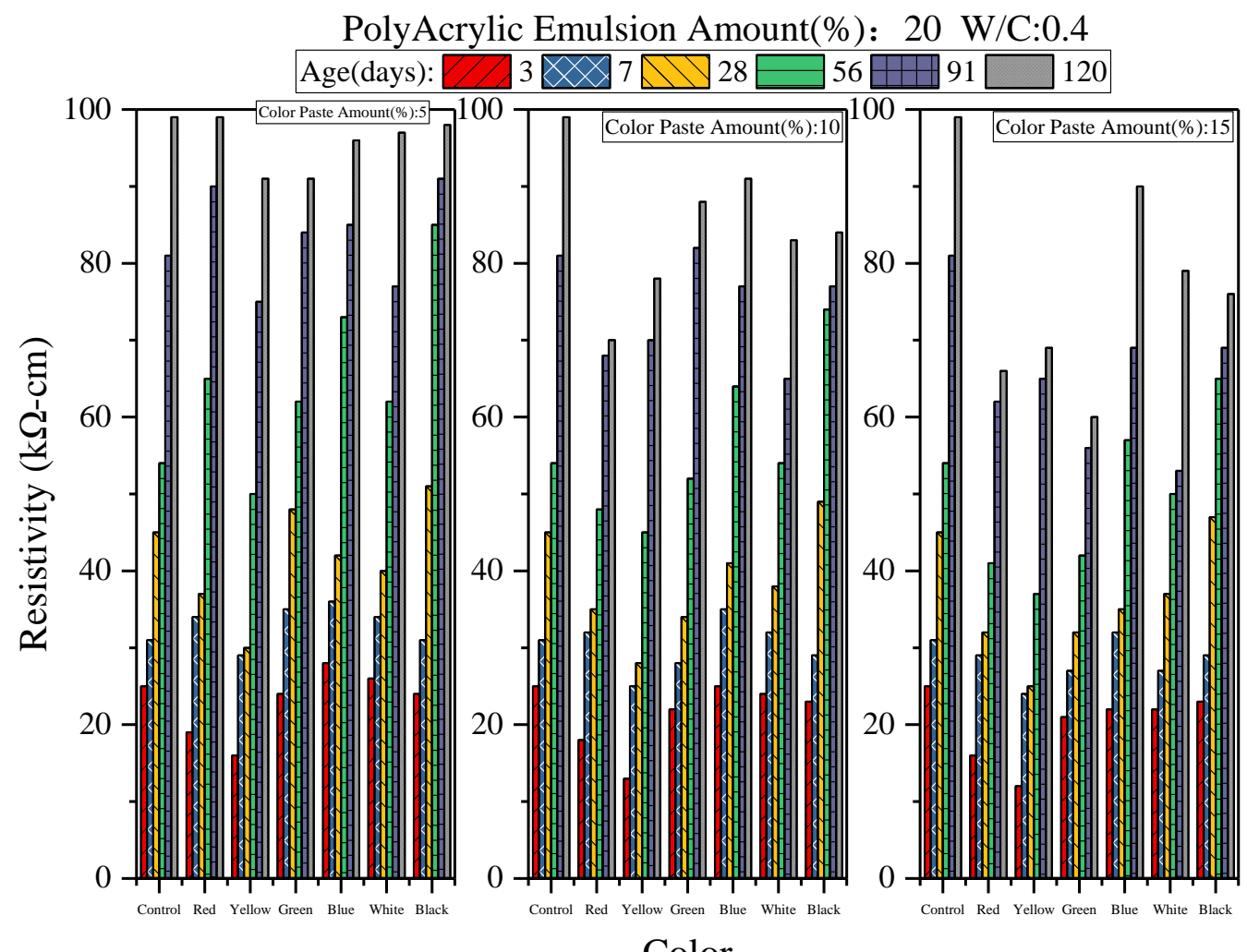

Figure 9. W/C 0.4 Resistivity of mortar with different proportions of inorganic color paste.

(8) Thermal conductivity

As shown in Figure 10, the thermal conductivities of the control group at the ages of 3 days, 28 days and 120 days are 2.3763, 3.0935 and $3.7238 \mathrm{~W} / \mathrm{m} \cdot \mathrm{K}$. When the content of inorganic color paste is $5 \%$ at the age of 3 days, the thermal conductivity is $1.5806 \sim 2.0724 \mathrm{~W} / \mathrm{m} \cdot \mathrm{K}$, that at the age of 28 days is $2.1275 \sim 2.8196 \mathrm{~W} / \mathrm{m} \cdot \mathrm{K}$, and that at the age of 120 days is $2.8784 \sim 3.2633 \mathrm{~W} / \mathrm{m} \cdot \mathrm{K}$. When the content of inorganic color paste is $10 \%$, the thermal conductivities at the ages of 3 days, 28 days and 120 days are $1.4074 \sim 1.8395 \mathrm{~W} / \mathrm{m} \cdot \mathrm{K}, 1.8413 \sim 2.3207 \mathrm{~W} / \mathrm{m} \cdot \mathrm{K}$ and $2.2758 \sim 2.9567 \mathrm{~W} / \mathrm{m} \cdot \mathrm{K}$. When the content of inorganic color paste is $15 \%$ at the age of 3 days, the thermal conductivity is $1.0044 \sim 1.5222 \mathrm{~W} / \mathrm{m} \cdot \mathrm{K}$, that at the age of 28 days is $1.4945 \sim 1.8162 \mathrm{~W} / \mathrm{m} \cdot \mathrm{K}$, and that at the age of 120 days is $2.0258 \sim 2.7202 \mathrm{~W} / \mathrm{m} \cdot \mathrm{K}$. The results show that the thermal conductivity of colorful mortar with various contents at various ages is lower than the control group. As the thermal conductivity decreases as the porosity increases, the polyacrylic emulsion forms manybubbles during mixing, forming many pores in the specimen, and the thermal conductivity decreases. As the colorful mortar hydration becomes completed, the inter- 
nal compactness of each specimen increases, so that the thermal conductivity increases with age.

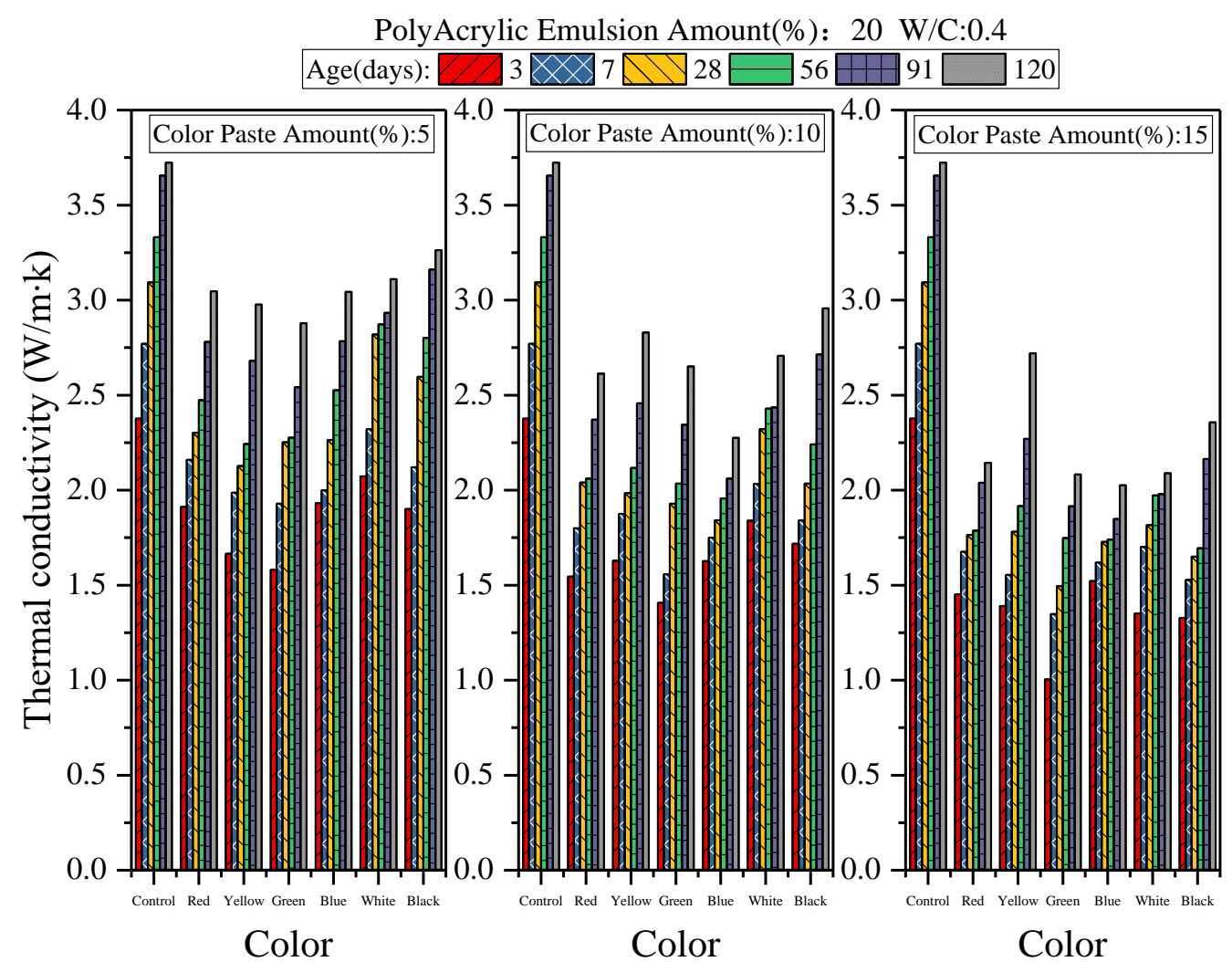

Figure 10. W/C 0.4 Thermal conductivity of mortar with different proportions of inorganic color paste.

(9) Length change

As shown in Figure 11, the length changes of the control group at the ages of 3 days, 28 days and 120 days are $-0.0451,-0.1001 \%$ and $-0.1299 \%$. When the content of inorganic color paste is $5 \%$ at the age of 120 days, the length changes of colors (red, yellow, green, blue, white, and black) are $-0.0931,-0.3724,-0.0814,-0.0407,-0.0417$ and $-0.0548 \%$. When the content of inorganic color paste is $15 \%$ at the age of 120 days, the length changes of colors (red, yellow, green, blue, white, and black) are $-0.1313,-0.7207$, $-0.1940,-0.0776,-0.1918$ and $-0.3542 \%$. The results show that, when the content of inorganic color paste is $15 \%$, the length is shortened obviously, and the content of yellow inorganic color paste has relatively significant dry shrinkage; this may because the content influences the water-cement ratio. 


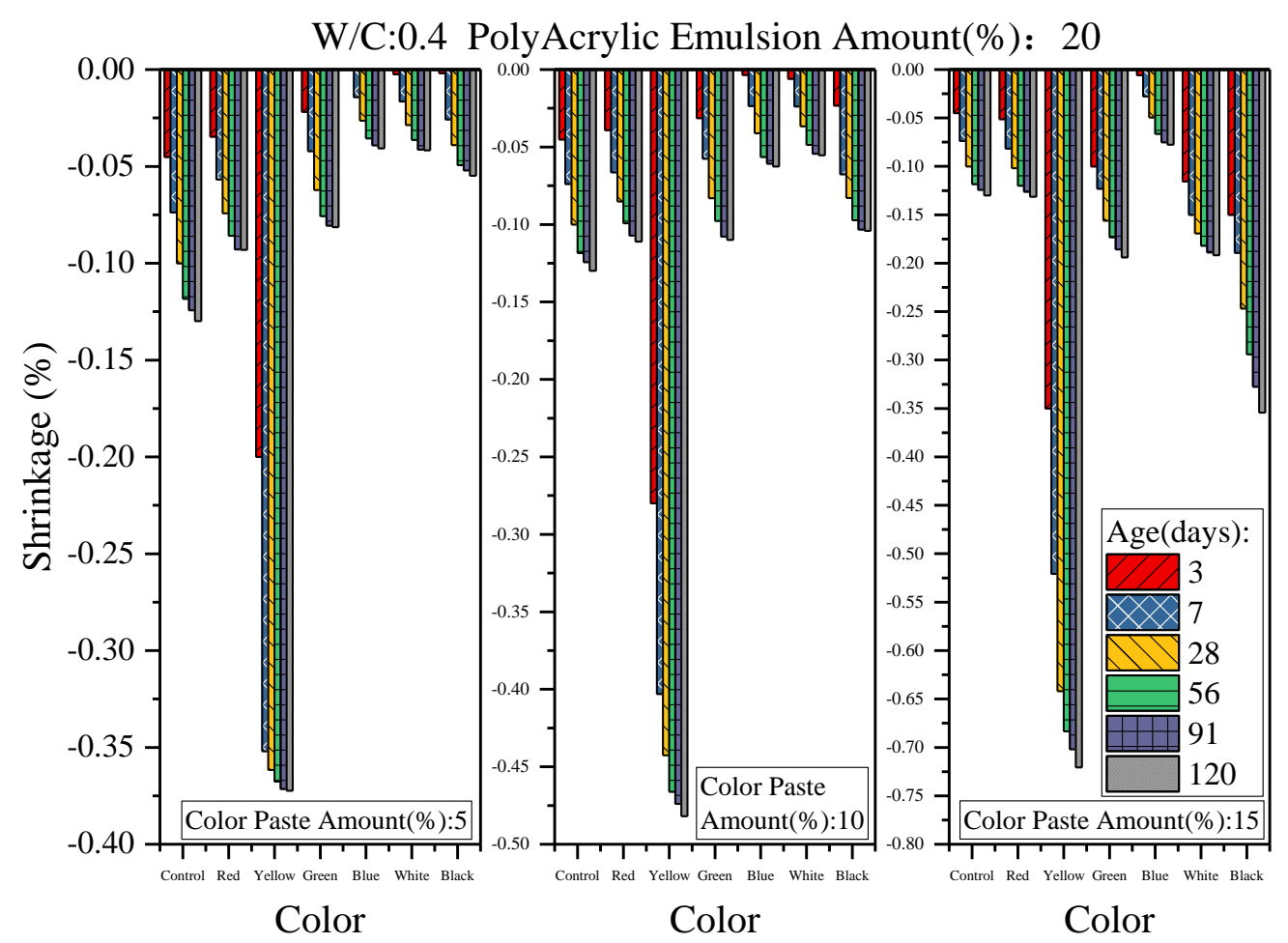

Figure 11. W/C 0.4 Shrinkage of mortar with different proportions of inorganic color paste.

\section{Conclusions}

1. The slump and slump flow increase with the content of inorganic color paste. The black inorganic color paste has the best fresh properties, the yellow inorganic color paste takes second place, and the other colors have insignificant differences.

2. The compressive strength decreases as the content of inorganic color paste increases, meaning a high content of inorganic color paste has negative influence on hardened properties. The addition of polyacrylic emulsion can reduce the specimen compactness, and the hardened properties degrade accordingly. The yellow inorganic color paste is the most effective on compressive strength; the compressive strength exceeds the control group when the content is $5 \%$. The green inorganic color paste is the least effective on compressive strength.

3. The flexural strength and tensile strength decrease as the content of inorganic color paste increases. The polyacrylic emulsion can improve the flexural strength and tensile strength of mortar. The strengths increase at later ages, and even exceed the control group.

4. The ultrasonic pulse velocity increases with age. The ultrasonic pulse velocity of colorful mortar with inorganic color paste is lower than the control group. Because the polyacrylic emulsion reduces the specimen compactness, the ultrasonic pulse velocity is lower than $4400 \mathrm{~m} / \mathrm{s}$. The content $5 \%$ of yellow inorganic color paste has the highest ultrasonic pulse velocity $(4321.33 \mathrm{~m} / \mathrm{s})$, the content $15 \%$ of green inorganic color paste has the lowest ultrasonic pulse velocity $(3750.33 \mathrm{~m} / \mathrm{s})$.

5. The resistivity decreases as the content of inorganic color paste increases. The trend of resistivity is different from the ultrasonic pulse velocity at late age. As the specimen shall be wet in quadrupole-type resistance measurement, the curing environment of this experiment is atmosphere, the specimen is too dry, and the measured resistivity is too high.

6. The thermal conductivity and length change decrease as the content of inorganic color paste increases. The addition of polyacrylic emulsion results in pores in the specimen, so that the thermal conductivity decreases. Various colors have insignificant 
differences in length change. There is no significant difference between the length change and the control group.

7. The addition of inorganic color paste will slightly reduce the hardening properties of the colored cement mortar, but the addition of $5 \%$ inorganic color paste can effectively improve the properties of the fresh mix. In this study, adding 20\% PolyAcrylic Emulsion can improve the engineering properties (flexural strength, tensile strength) and durability of the colored cement mortar, and achieve the advantages of workability, durability and aesthetics.

Author Contributions: Resources, J.-M.H.; writing—original draft preparation, T.-C.K.; writingreview and editing, H.-Y.W.; project administration, W.-D.Y. All authors have read and agreed to the published version of the manuscript.

Funding: This research was funded by Ministry of Science and Technology, grant number 109-2622E-992-005-CC3.

Conflicts of Interest: The authors declare no conflict of interest.

\section{References}

1. Hu, J.-J. Study on the Engineering Properties of Colored Cement Mortar. Master's Thesis, National Pingtung University of Science and Technology, Neipu, Taiwan, 2011.

2. Jiang, Z.-R. Key Success Factor for the Renovation on the outer Wall of Old buildings applying the Double Wall Rehabilitation Technique. Master's Thesis, China University of Science and Technology, Taipei, Taiwan, 2017.

3. Jiang, Z.-Y. A Study on the Discussion on the Shortage of Construction Workers from the Perspective of Engineering Personnel. Master's Thesis, National Kaohsiung University of Science and Technology, Kaohsiung City, Taiwan, 2020.

4. Feng, L.; Peng, Z.; Fei, Y. Discussion on application of color cement in military camouflage. New Chem. Mater. 2004, 9, 42-43.

5. Dow, C.; Glasser, F. Calcium carbonate efflorescence on Portland cement and building materials. Cem. Concr. Res. 2003, 33, 147-154. [CrossRef]

6. Pel, L.L.; Huinink, H.H.; Kopinga, K.K.; Van Hees, R.R.; Adan, O.O. Efflorescence pathway diagram: Understanding salt weathering. Constr. Build. Mater. 2004, 18, 309-313. [CrossRef]

7. Pel, L.L.; Huinink, H.H.; Kopinga, K.K. Salt transport and crystallization in porous building materials. Magn. Reson. Imaging 2003, 21, 317-320. [CrossRef]

8. Jhang, F.-D. Application of Pigments in Colored Concrete; China Concrete and Cement Products: Suzhou, China, $2009 ;$ pp. 50-53.

9. Liu, K.-T. Applicability of Epoxy Resin and Acrylic Resin Pastes for Repairing Cracks. Master's Thesis, National Taiwan Ocean University, Keelung, Taiwan, 2011.

10. ASTM C150, Standard Specification for Portland Cement; ASTM: Philadelphia, PA, USA, 2009.

11. ASTM C1602, Standard Specification for Mixing Water Used in the Production of Hydraulic Cement Concrete; ASTM: Philadelphia, PA, USA, 2018.

12. ASTM C33, Standard Specification for Concrete Aggregates; ASTM: Philadelphia, PA, USA, 2018.

13. ASTM C143, Standard Test Method for Slump of Hydraulic-Cement Concrete; ASTM: Philadelphia, PA, USA, 2020.

14. ASTM C230, Standard Specification for Flow Table for Use in Tests of Hydraulic Cement; ASTM: Philadelphia, PA, USA, 2008.

15. ASTM C109, Standard Test Method for Compressive Strength of Hydraulic Cement Mortars (Using 2-in. or [50-mm] Cube Specimens); ASTM: Philadelphia, PA, USA, 2020.

16. ASTM C348, Standard Test Method for Flexural Strength of Hydraulic-Cement Mortars; ASTM: Philadelphia, PA, USA, 2013.

17. ASTM C190, Method of Test for Tensile Strength of Hydraulic Cement Mortars; ASTM: Philadelphia, PA, USA, 1985.

18. ASTM C597, Standard Test Method for Pulse Velocity Through Concrete; ASTM: Philadelphia, PA, USA, 2009.

19. ASTM C876, Standard Test Method for Corrosion Potentials of Uncoated Reinforcing Steel in Concrete; ASTM: Philadelphia, PA, USA, 2015.

20. ASTM E1225, Standard Test Method for Thermal Conductivity of Solids Using the Guarded-Comparative-Longitudinal Heat Flow Technique; ASTM: Philadelphia, PA, USA, 2020.

21. ASTM C157, Standard Test Method for Length Change of Hardened Hydraulic-Cement Mortar and Concrete; ASTM: Philadelphia, PA, USA, 2017.

22. Chen, P.-J. The Impact of Acrylic Resin, Lightweight Coarse Aggregate Substitution Rate and Cementitious Material Composition on the Compressive Strength and Quality of Concrete. Master's Thesis, Kao Yuan University, Kaohsiung, Taiwan, 2015.

23. Huang, J.-L. Theory and Practice of High Performance Concrete; Chan's Arch-Publishing Co., Ltd.: Taipei City, Taiwan, 2006.

24. Wang, H.-Y.; Wang, W.-C.; Wang, J.C.; Chen, Y.-W. Evaluation of the engineering properties and durability of mortar produced using ground granulated blast-furnace slag and stainless steel reduced slag. Constr. Build. Mater. 2021, 280, 122498. [CrossRef] 